\title{
Educação e Mudança social: reflexões sobre o último meio século
}

Education and Social Change: reflections on the last half century

Educación y cambio social: reflexiones sobre el último medio siglo

\author{
Camila Ferreira da Silva \\ Universidade Federal do Amazonas (Brasil) \\ https://orcid.org/0000-0002-2348-9350 \\ http://lattes.cnpq.br/3520518346076110 \\ ferreira.camilasilva@gmail.com
}

Sebastião Juvêncio Rumbane

Escola de Jornalismo (Moçambique); Universidade Federal do Amazonas (Brasil)

Bolsista da Coordenação de Aperfeiçoamento de Pessoal de Nível Superior (Capes)

https://orcid.org/0000-0002-5139-3452

http://lattes.cnpq.br/7442349734345157

rsebastiaojuvencio@gmail.com

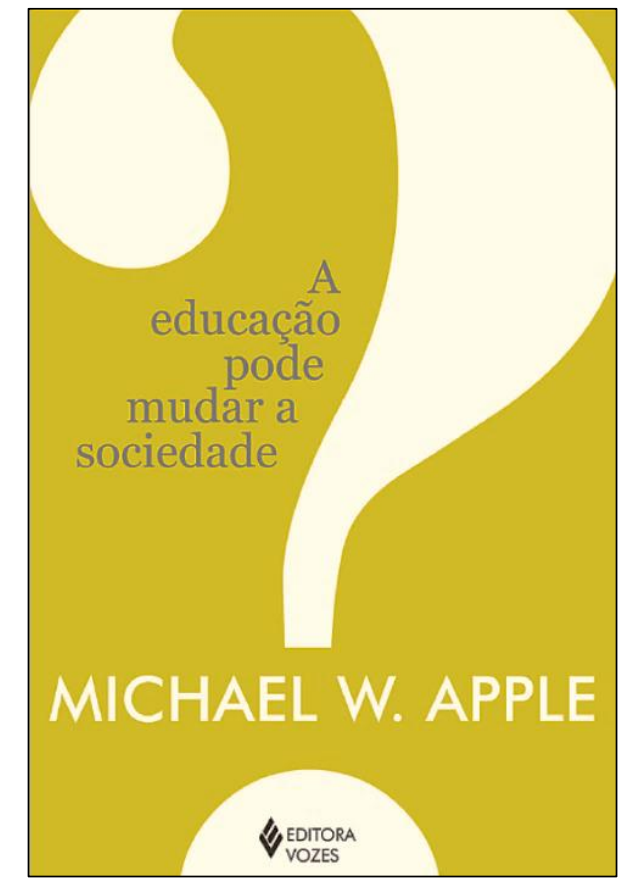

APPLE, Michael. A educação pode mudar a sociedade? Tradução de Lilia Loman. Petrópolis, RJ: Vozes, 2017. 310 pp. 
A educação, enquanto área do conhecimento ou espaço acadêmico específico, tem sua história de constituição assinalada por uma confluência de diferentes campos do saber e notadamente seu caráter multirreferencial exprime uma de suas principais marcas, a qual vem sendo reiterada em diferentes épocas e contextos acadêmicos e científicos (SILVA, 2017). Neste sentido, no último século temos assistido a uma multiplicação de subáreas, temas, objetos e de aportes epistêmicos, teóricos e metodológicos nas pesquisas educacionais. Naturalmente este cenário nos fala de uma diversidade de pesquisadores ocupados com questões bastante heterogêneas entre si, o que acaba por levantar uma interrogação: há algumas inquietações que liguem esses sujeitos? Poderíamos ensaiar algumas respostas para tal pergunta, e provavelmente nos encontraríamos ponderando sobre a importância da educação, seu papel nos âmbitos individual e social, seus sentidos para distintos grupos sociais e seus direcionamentos historicamente situados. Nessa linha, o professor Michael Whitman Apple tem se ocupado, mais detidamente desde a década de $1980^{1}$, a pensar o poder que a educação exerce na sociedade capitalista. Sua mais nova obra traduzida para o português e lançada no Brasil no final de 2017, "A educação pode mudar a sociedade?", constitui uma importante e madura produção nesta linha de pesquisa a que Michael Apple vem se dedicando há quase meio século, a presente resenha tem, pois, o objetivo central de apresentar criticamente a supracitada obra e o impacto de tal tradução para o público brasileiro e também para outros países de língua portuguesa.

Com mais de 350 artigos publicados e livros traduzidos em mais de 20 países, Michael Apple é um dos mais contundentes e influentes pensadores da atualidade no campo da educação. É professor catedrático dos departamentos de Currículo e Ensino e Estudos de Políticas Educacionais da Faculdade de Educação da Universidade Wisconsin-Madison nos Estados Unidos da América. Recebeu o título de Doutor Honoris Causa pela Universidad Nacional de Rosário, Argentina, e pela Universidade Federal do Rio Grande do Sul, Brasil, além de prêmios e medalhas de semelhante importância em países como China, Inglaterra, Canadá e Estados Unidos. Tem proferido palestras em vários países do mundo, tais como: Brasil, Canadá, Argentina, Inglaterra, Estados Unidos, China, Colômbia, Austrália - onde atuou como professor visitante em 2012 -, entre outros. Seu principal interesse, tanto na sua prática docente quanto em nível de investigações, tem se direcionado para as relações entre cultura e poder no âmbito da educação, é daqui que derivam seus temas de pesquisa e de publicações, dentre os quais destacamos teoria do currículo, sociologia do currículo, democratização da educação e das escolas, política educacional e educação crítica.

Sua ligação com o Brasil deve-se a fatores ligados à internacionalização de sua produção, às palestras que têm proferido nas últimas décadas e ainda aos professores brasileiros que têm recebido para a realização de estágio pós-doutoral em Madison. Muitos de seus livros têm sido traduzidos para o Brasil e ganhado reedições consecutivas, entre eles podemos destacar "Ideologia e Currículo" (com 3.511 citações no Google Acadêmico), "Educação e Poder" (cuja primeira edição no Brasil data de 1989) e "Política cultural e Educação" (livro esgotado). Nesse sentido, o público brasileiro interessado em discutir educação e temas correlatos tem certa familiaridade com o pensamento de Michael Apple.

Por isso, o livro "A educação pode mudar a sociedade?"2 representa mais um diálogo que Apple trava com suas redes de pesquisa e com seus leitores brasileiros, e parece-nos um exercício reflexivo perfeitamente coerente com sua trajetória profissional e intelectual e com sua produção no sentido mais amplo: sua atuação acadêmica sempre esteve atrelada a uma atitude crítica diante

\footnotetext{
${ }^{1}$ Faz-se mister registrar que a obra de Michael Apple, de modo mais amplo, vem se fazendo influente no campo da educação desde a década de 1970 (GANDIN; LIMA, 2016).

${ }^{2}$ Do original "Can Education change society?”, publicado em 2013 em New York (APPLE, 2013).
} 
do Capitalismo e do Neoliberalismo; sempre militou claramente ao lado das classes mais desfavorecidas, além de apoiar e estudar movimentos progressistas de transformação educacional e social. Isso nos leva a perceber que a pergunta que dá nome à obra que aqui resenhamos parece ter estado sempre presente, de modo indireto, na carreira de Michael Apple.

O livro está divido em oito capítulos, os quais ocupam-se do enfrentamento à pergunta que dá título à obra de formas complementares: a contextualização do cenário de emergência da relação entre educação e mudança social é seguida de um diálogo com autores como Paulo Freire, George Counts, Du Bois e Carter Woodson e ainda da análise de casos concretos de usos da educação em movimentos de transformação social e da reflexão sobre as dinâmicas do poder e o papel de um pensamento anti-hegemônico na educação. Apple demonstra sua visão sobre o poder da educação, que pode influenciar na produção de desigualdade sociais, mas que também, por outro lado, pode qualificar e mudar a sociedade. Neste sentido, o autor promove uma discussão rica com vários autores e suas diferentes perspectivas para introduzir seu entendimento sobre o que as escolas fazem, o que podem vir a construir e o que podemos fazer para desafiar a dominância e a subordinação na sociedade de modo geral.

No primeiro capítulo, o autor apresenta a pergunta central do livro, "A educação pode mudar a sociedade?" (serve aqui de título ao capítulo) e adianta respondendo que "[...] depende dos muitos, grandes e contínuos esforços feitos por muitas pessoas" (APPLE, 2017, p. 12). Esta resposta que o livro nos oferece já no seu início, apesar de parecer soar um tanto frustrante, traz três elementos cruciais, a saber: 1) não existe uma resposta única e absoluta para esta questão; 2) responder a tal interrogação somente pode ser realizado a partir de uma abordagem multifatorial e 3) a transformação e, principalmente, a direção desta transformação depende da correlação de forças que a engendra.

Este capítulo traz brevemente experiências de alguns países - a exemplo da Argentina, Eslovênia e os Estados Unidos - para explicitar os movimentos neoliberais nas políticas educacionais e suas influências nas escolas e nos espaços educativos ao redor do mundo (como a racialização das crianças e jovens, o uso racional dos estereótipos negativos para remoção de determinados sujeitos das escolas, as reformas educacionais privatistas, etc.), de um lado, e, para reafirmar que há grupos sociais que lutam contra esses efeitos de tais movimentos nas escolas, de outro. O lugar e o papel social das escolas é, pois, retomado por Michael Apple com o objetivo de demonstrar que, apesar das contradições que assolam esta instituição na sociedade capitalista atual - e aqui a tônica sociológica da relação mútua entre escola e sociedade ganha espaço com exemplos ligados principalmente ao gênero e à raça -, ela pode ser um espaço de ação, de mudança e de transformação social. Assim, o autor acredita na resistência coletiva dos movimentos sociais para impulsionar mudanças educacionais e transformar escolas e universidades em locais de transformação social e cultural.

A partir daqui, o autor inicia uma interlocução com outros pensadores que, em diferentes momentos e contextos, também acabaram por se colocar a questão do poder da educação no sentido da transformação social. No segundo capítulo do livro, "Paulo Freire e as tarefas do estudioso/ativista crítico na educação", Apple dialoga com Paulo Freire - uma das mais importantes figuras da educação crítica. Vida, obra e legado de Freire são mobilizados para tratar do compromisso de um educador crítico, que precisa se envolver em várias tarefas de análise crítica sobre a conexão entre a teoria e a prática educacional, ter em conta o contexto vivido, usar sua posição privilegiada para abrir espaços em universidades e em outros lugares para os que não têm voz e lutar pela justiça social. Proporcionando, dessa forma, a construção de uma educação coletiva anti-hegemônica e o desenvolvimento de atividades de conscientização para luta pela emancipação da educação. A questão que se coloca é como tornar a educação efetiva nas pessoas e transformadora da sociedade, tornando 
as práticas locais evidentes, se a educação está sujeita à globalização e ao pós-colonialismo liderado pelo Ocidente, que possui voz dominante em todos aspetos: geográfico, econômico, político e cultural. Isto resulta em disparidades nos currículos educacionais, porque por um lado é preciso assumir o que o Ocidente determina e, por outro, é necessário ter em conta o contexto local. Por conseguinte, na visão de Paulo Freire, qualquer trabalho educacional que não se baseia nas realidades locais, pode se tornar um ato de colonização. É aqui que Michael Apple estabelece uma ligação entre o trabalho de Paulo Freire e a emergência de teorias e experiências pós-coloniais, globalização e pedagogia crítica.

No terceiro capítulo, "George Counts e a política de mudança radical", o autor dialoga com George Counts, figura de destaque nos Estados Unidos quanto as ideias sobre transformação social. O pensamento de Counts, baseado no papel da escola como local de luta contra exploração e dominação dos oprimidos, perante crise econômica distributiva e ataques ideológicos conservadores em que nos encontramos, é tomado aqui por Apple para demarcar a importância de se considerar a relação entre economia (e aqueles responsáveis por ela) e educação e a necessidade de posicionamento, luta e superação da ideia de neutralidade por aqueles que acreditam na transformação que a educação pode provocar. Perante essa situação o autor revela ser necessário instigar os alunos para estabelecerem conexão entre o pessoal (o que se vive na sociedade) e o político (classe dominante), situação difícil de concretizar, uma vez que parece que a educação tende a desconectar-se da sociedade à sua volta para atender a interesses capitalistas que favorecem a classe dominante. Fica evidente que essas duas situações divergentes levam ao enfraquecimento da democracia e dão espaço ao individualismo, o que coloca em causa os valores coletivos e cooperativos que devem ser incutidos na escola para que a educação sirva para uma sociedade transformadora. Desta forma, a batalha contra a tendência capitalista na educação deve ocorrer dentro e fora da escola.

No capítulo seguinte, denominado "Du Bois, Woodson e a política da transformação", o autor dialoga com Du Bois e Carter Woodson, dois pensadores que se aproximam aqui pelo objeto comum de suas pesquisas e publicações, a realidade, a cultura e a educação das crianças e jovens negros nos Estados Unidos. Du Bois, tratando especificamente do sul dos Estados Unidos, acredita na perigosidade de um negro educado, pois este seria capaz de manifestar sua insatisfação e descontentamento quando violados seus direitos. Entretanto, pela pressão crescente dos movimentos sociais negros contra a classe dominante branca, $\mathrm{Du}$ Bois aponta que se aprofundou a segregação no ensino público, tornando os conteúdos e orientação ideológicas limitados para os negros de modo a mantê-los submissos. Essa segregação se concretizaria através de reformas curriculares que só tornariam os negros mais marginalizados e manteria a supremacia branca. A posição de Du Bois é de que o conhecimento dominante seja reorientado para resolução dos problemas sociais, culturais, políticos e econômicos que assolam as comunidades oprimidas e que ajude a resolvê-los.

Entretanto, o autodidata Woodson teve uma contribuição substancial para repensar questões como a História da Educação, a escravidão, a migração afro-americana, o profissionalismo negro $\mathrm{e}$ as experiências religiosas negras, tendo como princípios orientadores as necessidades das comunidades negras e criticando fortemente o foco eurocêntrico dos currículos escolares. Perante essa situação, Woodson notou a relevância de equipar professores com conhecimentos e valores e posteriormente introduzir um curso sobre história negra como modo de reagir contra o racismo mordaz da sociedade norte-americana. E, por conseguinte, Apple aponta que ambos [Du Bois e Woodson] concordavam que o enorme número dos intelectuais e filantrópicos brancos de seu tempo, embora apoiassem os esforços acadêmicos e culturais negros, atribuíam aos negros inferioridade social e intelectual. 
Após o diálogo com os pensadores apresentados nos capítulos anteriores, quinto e sexto capítulos passam a se debruçar sobre exemplos concretos de correlação entre educação e transformação social. No quinto capítulo, "Mantendo transformações vivas - aprendendo com o "Sul'", único capítulo em que Apple figura como coautor juntamente com Luís Armando Gandin, confere ênfase à gestão participativa na escola, tendo como exemplo o município de Porto Alegre (RS, região Sul do Brasil), em que se implementou uma administração popular que proporcionou uma relação vital entre Estado, escola e comunidade que vive nas favelas. Essa experiência consistiu em envolvimento da comunidade local nos anseios da escola para que esta servisse como local de debate dos problemas da sociedade. Nesse sentido, para melhor transparência, o Partido dos Trabalhadores criou uma "Escola Cidadã" e um conselho para gestão do orçamento participativo, órgão deliberativo responsável pela decisão e alocação de recursos orçamentários para investimento.

O processo de democratização em Porto Alegre exigia a participação total de professores, funcionários, pais e administradores na tomada de decisões e na monitoria com vista a garantia conjunta da implementação das ações deliberadas. Estes intervenientes deviam ser indagadores ativos do sistema educativo, influenciand o desta forma para capitalizar os problemas que assolam a sociedade, propondo soluções transformadoras e duradouras, isto é, que proporcionam um impacto positivo na vida social, econômica, política e cultural. Portanto, Apple e Gandin revelam que Porto Alegre demonstrou, com todas as contradições que o processo foi capaz de evidenciar, que era possível ter uma democracia mais densa, mesmo em tempos de crise econômica e ataques ideológicos de partidos neoliberais e da imprensa conservadora.

Já no sexto capítulo, denominado “A 'walmartização' da América - mudança social e ação educacional", o autor se debruça sobre a realidade norte-americana, no que tange ao processo de walmartização da educação nos Estados Unidos, que consiste em colocar escolas e a mídia a serviço das necessidades da sociedade corporativa. Apple se apoia na análise de Moreton, segundo o qual o desenvolvimento histórico de walmart concebeu diferentes e complexas relações econômicas, crescimento de empreendedorismo cristão, mudanças de trabalho e de formas de gerenciamento, criando conexões entre instituições do ensino superior locais, regionais e religiosas consideradas conservadoras, modificando, de um lado, os currículos destas instituições para que disciplinas sobre negócios e finanças fossem dominantes, e constituindo, de outro, formas de mobilização de estudantes - a exemplo da organização denominada "Students in Free Enterprise" (SIFE), grupo pró-business que se dedicava à educação econômica em todos níveis do sistema educacional, considerava a fé como a base das suas concepções e muitos de seus membros partilhavam de um conservadorismo cristão. Além de uma confusão no âmbito das fronteiras entre "[...] o público e o privado, a religião e o Estado, a religião e os negócios, os negócios e os outros aspectos da vida diária [...]" (APPLE, 2017, p. 223), o caso norte-americano evidencia que este processo de "walmartizar" a educação tem contribuído para a perda da identidade e de valores educacionais, posto que as tônicas de universalização do conhecimento, formação humana ou mesmo de liberdade têm sido substituídas por teses de privatização, marquetização, prestação de serviços e lucro.

Em "Educação crítica - Falando a verdade e reagindo", sétimo capítulo, Apple relata sua experiência como palestrante no Instituto Nacional da Coreia do Sul, em que vivenciou a ferocidade de um governo militar opressivo. Este viu seus movimentos totalmente controlados desde a sua aterragem, o decurso das palestras, locais de convívio e até seu alojamento estava sob controle do aparato policial e militar. Entretanto, foi substancial a vontade e a presença 
dos coreanos nas suas palestras ${ }^{3}$, embora o governo repressivo militar tivesse limitado seu acesso e, mesmo os que puderam aceder ao instituto, estavam rodeados e vigiados por militares civis e fardados que controlavam seus movimentos. Como se não bastasse, impediam que livros de Michael Apple sobre conhecimento e poder fossem lidos. Em contrapartida, isso influenciou para que estes continuassem ainda mais relevantes, uma lição que os governos repressivos ainda devem aprender.

Já no oitavo e último capítulo, "Respondendo à pergunta sobre educação e transformação social", o autor ratifica que a educação, as instituições educacionais e seus agentes podem agir para a mudança social, a questão a ser reconstruída ao final do livro seria: em que direção esta mudança está se desenhando? Michael Apple revela sua visão educacional de que esta não deve ser vista somente sob o ponto de vista capitalista, ou seja, puramente econômico, mas sim e sobretudo sob a sua face social, que geralmente é reivindicada pelos movimentos sociais críticos representados por professores, estudantes, juventudes, pais e membros da comunidade. Para Apple, esses sujeitos, num esforço coletivo, podem resistir e exigir para que o Estado implemente ações educacionais que tenham efeito direto nas pessoas e na democratização da sociedade. Vemos neste capítulo o autor defender mais detidamente que as escolas se tornem laboratórios de transformação social, pessoal e para o desenvolvimento de formas culturais e políticas anti-hegemônicas.

Por último, Apple retoma sua posição sobre educação transformadora, a qual pode ser materializada por meio da implementação efetiva da gestão participativa nas escolas e pela aproximação entre o local, o vivenciado e o que é ensinado nas escolas. Aumentar o envolvimento de cidadãos na vida pública, tornar políticas sociais mais justas e melhorar a eficácia do governo quanto à concepção e execução de políticas sociais, estes são alguns dos principais elementos defendidos pelo autor. Por conseguinte, e com mesmo grau de importância, os movimentos sociais, os professores e ativistas no geral devem agir como voz da população oprimida, as escolas devem, então, funcionar como locais de grandes mudanças sociais, respeitando as diferenças, implementando uma gestão democrática e resistindo à incorporação de formas de educação dominantes e excludentes.

O livro, pela sua envergadura dupla - teórica e ativista -, é indispensável não só para o campo acadêmico, mas para qualquer pessoa que se interesse pela educação. $\mathrm{O}$ autor traz sua visão ampla sobre o poder da educação escolar, que não deve ser vista apenas como local de preparação para o emprego, isto é, sob ponto de vista economicista, mas também social, político e ético. A escola deve ser local aberto de debate sobre os problemas sociais e de valorização de cada membro da sociedade como elemento integrante e fundamental para mudança social, sem distinção de gênero nem raça.

Ademais, um elemento presente nos agradecimentos do livro merece destaque: o autor inicia a obra afirmando que todos os livros são conquistas coletivas e arremata tal ideia com os muitos sujeitos que se fazem presentes nas páginas desta obra, são familiares, colegas de trabalho, estudantes, movimentos sociais e editores. Chama atenção neste espaço o denominado "Seminário de Sextas-feiras" na University of Wisconsin, no qual Michael Apple encontra-se com estudantes de pós-graduação, professores-visitantes e demais interessados para discutir questões políticas e educacionais, o autor indica que deve grande parte do seu trabalho e reflexões presentes em suas obras a este seminário - em tempos de produtivismo acadêmico, a construção de conhecimento de forma coletiva no cotidiano da universidade pode ser considerada um ato de resistência e poderia ser tomada como mais um dos elementos para pensar se a educação pode efetivamente mudar a nossa sociedade.

\footnotetext{
${ }^{3}$ No que tange às palestras proferidas, o governo militar repressivo havia pedido que Apple enviasse com maior antecedência o texto de modo que fosse censurado para evitar que o palestrante passasse dos limites por eles considerados aceitáveis. E que durante a exposição, devia seguir o rigor acadêmico.
} 


\section{Referências}

APPLE, Michael. A educação pode mudar a sociedade? Petrópolis, RJ: Vozes, 2017.

APPLE, Michael. Can education change society? New York: Routledge, 2013. https://doi.org/10.4324/9780203083550

GANDIN, Luís Armando; LIMA, Iana Gomes. A perspectiva de Michael Apple para os estudos das políticas educacionais. Educ. Pesqui., São Paulo, v. 42, n. 3, p. 651-664, jul./set. 2016. Disponível em: https://www.redalyc.org/pdf/298/29847323005.pdf. Acesso em: 12 fev. 2020.

SILVA, Camila Ferreira. (Ciências da) Educação no Brasil e em Portugal: autonomização dos espaços acadêmicos específicos. 333f. 2017. Tese (Doutorado em Ciências da Educação) - Faculdade de Ciências Humanas e Sociais, Universidade Nova de Lisboa, Lisboa, 2017. Disponível em: https://run.unl.pt/handle/10362/23001. Acesso em: 12 fev. 2020. https://doi.org/10.1590/S1517-9702201609143447 